\title{
BMJ
}

\section{Errors in administration of parenteral drugs in intensive care units: multinational prospective study}

Andreas Valentin, associate professor ${ }^{1}$, director of intensive care unit, ${ }^{2}$ Maurizia Capuzzo, consultant in
anaesthesia and intensive care medicine, ${ }^{3}$ Bertrand Guidet, professor, ${ }^{45}{ }^{6}$ Rui Moreno, professor, ${ }^{7}$ Barbara
Metnitz, statistician, ${ }^{8}$ Peter Bauer, professor and head of core unit of medical statistics and informatics, ${ }^{8}$
Philipp Metnitz, professor ${ }^{9}$ on behalf of the Research Group on Quality Improvement of the European
Society of Intensive Care Medicine (ESICM) and the Sentinel Events Evaluation (SEE) Study Investigators

\section{ABSTRACT}

'Department of Emergency Medicine, Medical University of Vienna, Vienna, Austria

${ }^{2}$ Rudolfstiftung Hospital, Medical Department II, Juchgasse 25, A-1030 Vienna

${ }^{3}$ Department of Anaesthesia and Intensive Care, University Hospital of Ferrara, Ferrara, Italy

${ }^{4}$ INSERM, Unité de Recherche en Epidemiologié, Systemes d'Information, et Modelisation,

Paris, France

${ }^{5}$ Faculty of Medicine, University Pierre et Marie Curie, Paris

${ }^{6}$ Assistance Publique, Hôpitaux de Paris, Hôpital Saint-Antoine,

Service de Réanimation Médicale, Paris

${ }^{7}$ Department of Intensive Care, Hospital de St António dos Capuchos, Centro Hospitalar de Lisboa (central, e.p.e), Lisbon, Portugal

${ }^{8}$ Section of Medical Statistics, Medical University of Vienna, Vienna

${ }^{9}$ Department of Anaesthesiology and General Intensive Care Medical University of Vienna, Vienna

Correspondence to: A Valentin andreas.valentin@meduniwien.ac.at

Cite this as: $B M J$ 2009;338:b814 doi:10.1136/bmj.b814
Objective To assess on a multinational level the frequency, characteristics, contributing factors, and preventive measures of administration errors in parenteral medication in intensive care units.

Design Observational, prospective, 24 hour cross sectional study with self reporting by staff.

Setting 113 intensive care units in 27 countries.

Participants 1328 adults in intensive care.

Main outcome measures Number of errors; impact of errors; distribution of error characteristics; distribution of contributing and preventive factors.

Results 861 errors affecting 441 patients were reported: 74.5 (95\% confidence interval 69.5 to 79.4 ) events per 100 patient days. Three quarters of the errors were classified as errors of omission. Twelve patients $(0.9 \%$ of the study population) experienced permanent harm or died because of medication errors at the administration stage. In a multiple logistic regression with patients as the unit of analysis, odds ratios for the occurrence of at least one parenteral medication error were raised for number of organ failures (odds ratio per increase of one organ failure: $1.19,95 \%$ confidence interval 1.05 to 1.34 ); use of any intravenous medication (yes $v$ no: $2.73,1.39$ to 5.36 ); number of parenteral administrations (per increase of one parenteral administration: $1.06,1.04$ to 1.08 ); typical interventions in patients in intensive care (yes $v$ no: 1.50 , 1.14 to 1.96); larger intensive care unit (per increase of one bed: $1.01,1.00$ to 1.02); number of patients per nurse (per increase of one patient: $1.30,1.03$ to 1.64$)$; and occupancy rate (per $10 \%$ increase: $1.03,1.00$ to 1.05 ). Odds ratios for the occurrence of parenteral medication errors were decreased for presence of basic monitoring (yes $v$ no: $0.19,0.07$ to 0.49 ); an existing critical incident reporting system (yes $v$ no: $0.69,0.53$ to 0.90 ); an established routine of checks at nurses' shift change (yes $v$ no: $0.68,0.52$ to 0.90 ); and an increased ratio of patient turnover to the size of the unit (per increase of one patient: $0.73,0.57$ to 0.93 ).

Conclusions Parenteral medication errors at the administration stage are common and a serious safety problem in intensive care units. With the increasing complexity of care in critically ill patients, organisational factors such as error reporting systems and routine checks can reduce the risk for such errors.

\section{INTRODUCTION}

Although the classic medical principle of "first do no harm" refers primarily to the balance of risks and benefits of a specific treatment, it also fits a more general approach to the practice of medicine. This was highlighted by a recent investigation of 21 hospitals in the Netherlands showing that nearly $6 \%$ of 1.3 million hospital admissions in 2004 resulted in unintentional harm to the patient. ${ }^{1}$ The combination of complexity and the potential for great harm makes medicine, especially intensive care, even more fraught with risk than other high complexity areas such as aviation. ${ }^{2}$ Although patients' safety is increasingly recognised as an essential component in the practice of intensive care medicine, the complexity of processes and medical conditions dealt with makes the practice of this specialty vulnerable and prone to error. ${ }^{34}$ In the recently published first multinational sentinel events evaluation (SEE 1) study, 38.8 incidents per 100 patient days in five selected categories (drains and lines, artificial airway, equipment, handling of alarms, and medication) were observed in 205 participating intensive care units. ${ }^{5}$ In that 24 hour cross sectional study, medication errors at the prescription and administration stages were reported by unit staff at a rate of 10.5 per 100 patient days. As such errors carry a particularly high potential for serious harm, this topic was chosen for the second multinational sentinel events evaluation study (SEE 2).

We conducted a prospective, observational, multinational study on the frequency, characteristics, and contributing factors of parenteral medication errors at the administration stage in intensive care units. We used a cross sectional design with a 24 hour observation period to ensure a concentrated focus on data collection. In addition, we assessed the impact of parenteral medication errors and the outcome of patients exposed to such errors. 


\section{METHODS}

This study was conducted by the research group on quality improvement of the European Society of Intensive Care Medicine (ESICM). Participating units chose one of two available study days (either 17 January or 24 January 2007) with a 24 hour observation period. Ultimately, 113 units from 27 countries on five continents participated. Thirty five of these units had participated in the first study in January 2004.

\section{Definition, assessment, and description of medication} errors at the administration stage

A medication error at the administration stage was defined as an error of omission or commission in the context of parenteral drug administration that harmed or could have harmed a patient. We exclusively addressed medication errors that were attributable to five types of error during the stage of administration: wrong dose, wrong drug, wrong route, wrong time, missed medication. Errors were further classified by type of drug administration (intravenous bolus, intravenous continuous, subcutaneous) and class of drug (sedation/analgesia, vasopressors/catecholamines, antimicrobial, coagulation related, electrolytes, insulin, others).

All nurses and physicians on duty in the participating units during the 24 hour study period were asked to fill in a single questionnaire available at the bedside of each patient. The questionnaire for each patient could therefore contain consecutive entries from several staff members. Every contributor to the questionnaire could see which medication errors, if any, were already reported, making duplicate reporting highly unlikely. The structured questionnaire asked if, and at what time, an error in parenteral medication had occurred. The questionnaire also asked for a formalised and coded description of every medication error so that we could assess contributing factors (communication-written, communication-oral, handover, workload/stress/fatigue, experience/knowledge/supervision, violation of protocol/standard, recently changed brand name of drugs, equipment failure, others); situational factors (admission/discharge, routine, emergency, movement with the hospital, intervention, urgent crisis of another patient, others); and grading of the impact of the error (a change registered or not, intervention necessary or not, no harm, temporary harm, permanent harm, death). For each error, we asked three questions: Were formal requirements for secure drug prescription fulfilled $?^{67}$ Were trainees involved? and Did the same person both prepare and administer the drug?

A coordinator in each participating unit was responsible for briefing the team and transmitting the data. The coordinator's obligations included the provision of information regarding characteristics of the unit, the actual staffing and patient flow during the study period, and the classification of the severity of illness and medical personnel workload for every patient. In addition, the coordinator assessed and reported the vital status of every patient at discharge from the unit, or on day 28 after the study period ended
Table 1|Final study sample: number of participating intensive care units, number of patients, and corresponding countries

\begin{tabular}{|c|c|c|}
\hline Country & No of units & No of patients \\
\hline Argentina & 3 & 58 \\
\hline Australia & 1 & 16 \\
\hline Austria & 17 & 109 \\
\hline Belgium & 2 & 50 \\
\hline Belize & 1 & 4 \\
\hline Brazil & 3 & 60 \\
\hline Czech Republic & 2 & 29 \\
\hline Finland & 1 & 7 \\
\hline France & 6 & 54 \\
\hline Germany & 9 & 246 \\
\hline Greece & 2 & 9 \\
\hline Iran & 1 & 9 \\
\hline Ireland & 1 & 11 \\
\hline Italy & 20 & 133 \\
\hline Netherlands & 2 & 21 \\
\hline New Zealand & 1 & 4 \\
\hline Poland & 1 & 3 \\
\hline Portugal & 4 & 34 \\
\hline Romania & 1 & 6 \\
\hline Saudi Arabia & 1 & 22 \\
\hline Singapore & 1 & 6 \\
\hline Slovakia & 1 & 8 \\
\hline Spain & 8 & 128 \\
\hline Sweden & 2 & 10 \\
\hline Switzerland & 3 & 41 \\
\hline United Kingdom & 17 & 200 \\
\hline United States & 2 & 50 \\
\hline
\end{tabular}

if the patient was still in the unit. Data acquisition and reporting were anonymous for both patients and medical personnel. As a consequence, reported errors were not attributable to the type of medical professional involved, whether nurse or physician.

\section{Patients included}

The study included all patients staying in the participating units, including those admitted or discharged during the study period.

\section{Patient related factors}

For each patient, staff recorded basic demographic characteristics, as well as occurrence and descriptive factors of each parenteral medication error. To assess the range of opportunities for error (denominator), each single dose of parenteral medication given to each patient was counted. In medications with a continuous intravenous administration, each syringe for perfusion pumps or each infusion bottle was considered as a single dose.

To determine the severity of illness in each patient, the items necessary for calculating the sequential organ failure assessment (SOFA) score $^{8}$ were collected to quantify the presence and degree of organ dysfunction or failure and consequently provide a surrogate for severity of illness. The score takes into account the 
function of six organ systems (respiratory, renal, hepatic, cardiovascular, haematology, and central nervous system) as well as the weight of some therapeutic interventions (such as use of catecholamines). The items for the nine equivalents of nursing manpower use score $(\mathrm{NEMS})^{9}$ were recorded as a surrogate marker for the amount of nursing workload and consequently the level of care provided to each patient. The NEMS items are related to specific organ support and nursing and diagnostic or therapeutic interventions inside or outside the unit. Both scores were assessed for each patient on the day of the study.

Table 2 |Characteristics of 1328 patients in 113 intensive care units*

Median (IQR), No (\%), or mean (SD)

\section{Patients}

\begin{tabular}{lc}
\hline Mean (SD) age (years) & $62.6(16.2)$ \\
\hline Males (\%) & $797(60)$ \\
\hline Days in unit before observation & $2.5(0.5-11.0)$ \\
\hline SOFA score (points) & $5(2-8)$ \\
\hline NEMS score (points) & $27(18-34)$ \\
\hline Unit mortality (\%), censored on day 28 after study entry* & 17.5 \\
\hline Intensive care units &
\end{tabular}

\section{Intensive care units}

No (\%) by type of unit:

\begin{tabular}{lc}
\hline Mixed & $87(77)$ \\
\hline Medical & $12(11)$ \\
\hline Surgical & $8(7)$ \\
\hline Trauma & $4(4)$ \\
\hline Other & $2(2)$ \\
\hline
\end{tabular}

No (\%) by No of beds in unit:

\begin{tabular}{ll}
\hline 7 & $20(18)$ \\
\hline $7-12$ & $60(53)$ \\
\hline 12 & $33(29)$ \\
\hline
\end{tabular}

No (\%) by hospital size (beds):

\begin{tabular}{lc}
\hline 300 & $19(17)$ \\
\hline $300-600$ & $47(42)$ \\
\hline 600 & $47(42)$ \\
\hline No (\%) of nurses by shifts in 24 hours: & $44(39)$ \\
\hline Units with 2 shifts & $69(61)$ \\
\hline Units with 3 shifts & $1.3(1.0-1.8)$ \\
\hline Patients per nurse: & $1.6(1.2-2.0)$ \\
\hline Shift 1 & $2.0(1.4-2.5)$ \\
\hline Shift 2 & \\
\hline Shift 3 & $59(52)$ \\
\hline No of physicians by shifts in 24 hours: & $54(48)$ \\
\hline Units with 2 shifts & $2.6(2.0-4.0)$ \\
\hline Units with 3 shifts & $5.5(3.5-7.0)$ \\
\hline Patients per physician: & $6.0(4.0-8.0)$ \\
\hline Shift 1 & $100.0(83.3-100)$ \\
\hline Shift 2 & $94.1(80-100)$ \\
\hline Shift 3 & $92.6(80-100)$ \\
\hline Occupancy rate (\%): & \\
\hline Shift 1 & \\
\hline Shift 2 & \\
\hline Shift3 & \\
\hline
\end{tabular}

$\mathrm{IQR}=$ interquartile range; SOFA=sequential organ failure assessment score; $N E M S=$ nine equivalents of nursing manpower use score.

*Information missing in 26 patients (2\%).
The duration of each patient's stay in the unit was assessed from the time of admission to discharge and was reported as length of stay (days) before and after the observation period. In addition, the actual time (hours) a patient stayed in the unit during the observation period was reported. For the objective of measuring outcome, the vital status (alive or dead) was assessed at discharge or on day 28 after the study period ended if the patient was still in the unit.

\section{Intensive care unit related factors}

Characteristics of hospital size (beds), type and size (beds) of intensive care unit, shift schedule for nurses and physicians (start and end as time of day), number of nurses and physicians appointed to each shift, number of occupied and free beds in each shift, maximum number of patients in each shift, and number of admitted and discharged patients in each shift were recorded for every unit. These data allowed us to calculate occupancy rate (maximum number of occupied beds divided by allocated beds), relative turnover (number of admitted and discharged patients divided by the number of unit beds), and the ratios of patients to nurses and patients to physicians for each shift in each unit. Information about any existing system for formal critical incident reporting as well as any computerised medication prescribing system was also recorded. With respect to the process of parenteral medication administration, further information was obtained about the use of infusions previously prepared by a pharmacist, use of perfusors with a fixed standard preparation, existence of a dedicated area for preparation of medications, number of different types (different model or different manufacturer) of perfusors and infusion pumps, routine check of perfusor or infusion pumps at every shift change, and labelling of all syringes prepared with drugs before use.

\section{Database and data collection}

Patients' data were recorded on a dedicated project website (www.hsro-esicm.org) with online data collection software. The website contained all documentation, including detailed definitions of all data fields and events; data collection sheets available for download; and access to the study database with data entry forms. To ensure consistent quality of the data in units from different participating countries, the questionnaires and the descriptive list of items were available in six languages: English, German, Italian, French, Portuguese, and Spanish.

The appointed unit coordinator entered data collected from each unit on the study database. During data entry, the software automatically performed plausibility and completeness checks. Each variable was defined in detail before the start of data collection, and the definitions were available in both paper and electronic form. To facilitate plausibility checking, each variable was assigned a range of probable values and a range of possible values (storage range).

Data collection started at the beginning of the nurses' day shift. The study period was designed to overlap a 
Table $3 \mid$ Observed rates of parenteral medication errors

\begin{tabular}{lcc} 
& No of errors & Events $/ 100$ patient days ${ }^{\star}(95 \% \mathrm{Cl})$ \\
\hline Total & 861 & $74.5(69.5$ to 79.4$)$ \\
\hline Wrong time & 386 & $33.4(30.1$ to 36.7$)$ \\
\hline Missed medication & 259 & $22.4(19.7$ to 25.1$)$ \\
\hline Wrong dose & 118 & $10.2(8.4$ to 12.0$)$ \\
\hline Wrong drug & 61 & $5.3(4.0$ to 6.6$)$ \\
\hline Wrong route & 37 & $3.2(2.2$ to 4.2$)$ \\
\hline
\end{tabular}

*Patient days calculated as total time (hours) of observation for all patients divided by 24 .

second day (but not to exceed 24 hours) to ensure that data acquisition in each unit included at least one day shift and one night shift.

\section{Statistical analysis}

We used SAS, version 9.1 (SAS Institute, Cary, NC), for statistical analyses and considered $\mathrm{P}<0.05$ (two sided) as significant. Unless otherwise specified, descriptive results are expressed as medians and interquartile ranges.

Denominators were the number of all patients in the final study sample, the number of patients exposed to a specific item, the number of all units contributing patients to the final study sample, the number of patient days (calculated as total hours of observation for all patients, divided by 24), or the total number of doses of parenteral medication. The numerator was the number of patients experiencing a medication error or the number of medication errors in total or in different categories.

Odds ratios were calculated with a dichotomous outcome variable - no medication error versus occurrence of at least one medication error during the observation period-with the patient as the unit of analysis. We chose this simple variable because ordering by counting the number of events (for example, when using an ordered outcome variable as $0 v 1,2,3$, 4 , or more medication errors) is questionable because of the different characteristics and severity of events. Moreover, this simple analysis is unaffected by possible duplicate reports for the same event.

For the analysis according to the criteria of completeness of documentation and relevance for the practice of intensive care we chose patients' characteristics and characteristics of the intensive care unit (as

Table 4 |Classes of drugs and rates of associated errors

\begin{tabular}{lcc} 
Class & Administrations & No (\%*) of errors \\
Vasopressors and catecholamines & 702 & $57(8)$ \\
\hline Insulin & 757 & $42(6)$ \\
\hline Coagulation related & 1107 & $73(7)$ \\
\hline Electrolytes & 1450 & $82(6)$ \\
\hline Antimicrobial & 1905 & $179(9)$ \\
\hline Sedation and analgesia & 2136 & $181(9)$ \\
\hline Others & 3668 & $243(7)$ \\
\hline Total & 11725 & $857 \dagger(7)$ \\
\hline
\end{tabular}

*Proportion of administrations that resulted in errors.

tFour event classifications are missing. listed above). We used univariate logistic regression to evaluate univariate associations between these and the outcome. We included variables that reached univariate significance $(\mathrm{P}<0.05$ two sided $)$ in a stepwise multivariate logistic regression analysis (SAS option stepwise). Clustering on the patient level or unit level was accounted for by including various patient and unit related variables to explain differences between patients and units, respectively. To differentiate between errors, we performed the calculations separately for all types of errors, errors of commission (wrong drug, wrong dose, wrong route), and errors requiring an intervention. In all regression analyses $\mathrm{P}<0.05$ was considered significant.

\section{RESULTS}

Samples of intensive care units and patients

After exclusion of 57 patients under the age of 18 and 35 patients with conflicting information, the final study sample consisted of 1328 adult patients from 113 units in 27 countries (table 1). Table 2 gives details of patients' characteristics. Patients spent 0.6 to 24 hours in the unit during the 24 hour observation period, and only $23 \%$ spent less than 24 hours in the unit. A SOFA score of 5 - the median value in the patients - reflects in a given patient the dysfunction or failure of more than one organ system. A NEMS score of 27-the median value in the patients - reflects in a given patient an average level of care, or the equivalent of $59 \%$ of the workload that one unit nurse can perform in 24 hours.

Table 2 also describes the intensive care units. Most of the 113 units were mixed and were in hospitals with more than 300 beds. Nearly half the units $(48 \%)$ had an existing system in place for formal critical incident reporting.

\section{Process characteristics}

In $37(33 \%)$ units medication was prescribed by means of an electronic prescribing system. Further reporting showed that $26(23 \%)$ used infusions previously prepared by a pharmacist, $76(67 \%)$ used perfusors with a fixed standard preparation, $69(61 \%)$ provided a dedicated area for preparation of medications, 78 $(69 \%)$ routinely checked perfusors and infusion pumps at every shift change, and $97(86 \%)$ labelled all syringes prepared with drugs before use. The median number of different types (such as from different manufacturers) of perfusors and infusion pumps in use per unit was 2.0 (interquartile range 1.0-3.0 and 1.0-2.0, respectively).

\section{Occurrence and characteristics of errors}

In the 1328 patients, 861 medication errors affecting 441 patients were reported for the 24 hour study period. A total of 887 patients $(67 \%)$ experienced no error, $250(19 \%)$ experienced only one error, and 191 patients $(14 \%)$ experienced more than one. Of the 113 units, $21(19 \%)$ reported no medication errors.

There were 74.5 (95\% confidence interval 69.5 to 79.4) errors per 100 patient days. Table 3 gives the corresponding data for all categories of error. In the five categories, the most frequent errors were related to 
Table 5 |Medication errors* with reports of subsequent serious harm by respective class of drugs and type of error

\begin{tabular}{lccc} 
Medication & $\begin{array}{c}\text { Wrong time } \\
(\mathrm{n}=386)\end{array}$ & $\begin{array}{c}\text { Missed medication } \\
(\mathrm{n}=259)\end{array}$ & $\begin{array}{c}\text { Wrong dose } \\
(\mathrm{n}=118)\end{array}$ \\
$\begin{array}{l}\text { Vasopressors and } \\
\text { catecholamines }\end{array}$ & 0 & $1 \dagger$ & 0 \\
\hline Insulin & 0 & $1 \dagger$ & 0 \\
\hline Coagulation related & 0 & 0 & $1 \ddagger$ \\
\hline Electrolytes & 0 & $1 \dagger$ & 0 \\
\hline Antimicrobial & 0 & $2 \dagger$ & $2 \dagger$ \\
\hline Sedation and analgesia & 0 & 0 & $1 \dagger, 1 \ddagger$ \\
\hline Others & $2 \ddagger$ & $1 \dagger 1 \ddagger$ & $1 \ddagger$
\end{tabular}

*In one patient, two different errors with subsequent impact of death were reported. In another patient, three different errors with subsequent impact of permanent harm were reported.

†Permanent harm.

$\ddagger$ Died.

wrong time of administration $(\mathrm{n}=386)$ and missed medication $(\mathrm{n}=259)$, followed by wrong dose $(\mathrm{n}=118)$, wrong drug $(n=61)$, and wrong route $(n=37)$.

Medication errors at the administration stage occurred most frequently during routine situations $(\mathrm{n}=595 ; 69 \%)$ and least frequently during admission and discharge procedures $(\mathrm{n}=73 ; 8 \%)$, movement within the hospital $(\mathrm{n}=40 ; 5 \%)$, undefined situations $(\mathrm{n}=41 ; 5 \%)$, emergencies $(\mathrm{n}=38 ; 4 \%)$, interventions $(\mathrm{n}=36 ; 4 \%)$, and urgent crisis with another patient in the unit $(\mathrm{n}=29 ; 3 \%)$.

With respect to the type of administration, 505 medication errors occurred during 5622 intravenous bolus administrations (9\%), 279 during 5034 continuous intravenous administrations $(6 \%)$, and 69 during 1069 subcutaneous administrations (6\%); in eight events the route of administration was not specified. Aside from the group of unclassified drugs, most errors occurred in the classes of antimicrobial drugs and sedation or analgesia. Table 4 shows classes of drugs and rates of associated errors.

Unit staff reported workload/stress/fatigue as a contributing factor in $32 \%(n=272)$ of all errors. Other contributing factors were recently changed drug name $(\mathrm{n}=155 ; 18 \%)$, communication-written $(\mathrm{n}=124 ; 14 \%)$, communication-oral $(\mathrm{n}=83 ; 10 \%)$, experience/knowledge/supervision $(\mathrm{n}=81 ; 9 \%)$, violation of protocol/standard $(\mathrm{n}=76 ; 9 \%)$, handover $(\mathrm{n}=53$; $6 \%)$, equipment failure $(n=0)$, and others $(n=0)$.

\section{Reported impact of errors}

According to a predefined classification, participating units reported that $71 \%$ of parenteral medication errors resulted in no change in the status of the patient. In contrast, according to the review of reporting units, 12 patients $(0.9 \%$ of the total study population) experienced permanent harm $(n=7)$ or death $(n=5)$ in relation to a total of 15 medication errors at the administration stage. Table 5 shows the type of error and the class of drug involved in these 15 errors. In eight cases, trainees were reported as being involved. Unit mortality (reported up to day 28) was $14.5 \%$ and $22.8 \%$ in patients without and with a parenteral medication error, respectively. Mortality was not predicted by the occurrence of a parenteral medication error.

\section{Predictors of parenteral medication errors}

We calculated predictive variables of parenteral medication errors by using the dependent variable "occurrence of at least one medication error," with the patient as the unit of analysis, for all types of observed errors and for two subsets of error (errors of commission, errors requiring an intervention). Univariate analysis showed that a higher severity of illness, a higher level of care, and a higher rate of parenteral drug administrations were associated with increased odds for the occurrence of at least one medication error. These significant associations were seen in both all types of error and the two subsets of error.

With respect to unit related variables, the univariate analysis showed that, for all types of error and the two subsets of error (errors of commission, errors requiring intervention), the odds for the occurrence of at least one medication error were increased at a higher patient to nurse ratio and were decreased when a critical incident reporting system was already in place. Table 6 gives details of all unit related variables reaching significance in different sets of type of error.

In a stepwise multiple logistic regression analysis, six unit related and five patient related variables remained in the final model when we included all types of error. Table 7 gives details of this analysis as well as the analysis in subsets of types of error (errors of commission, errors requiring intervention). Again, a higher severity of illness, a higher level of care, and a higher rate of parenteral drug administrations were associated with increased odds for the occurrence of at least one medication error. Of note, results were robust for the influence of the existence of a critical incident reporting system both in the univariate and multivariate analysis for all three different sets of type of error. There was only one exception in the multivariate analysis, where "electronic prescribing system"was the only significant unit related variable. In this case, however, the variable "electronic prescribing system" might well cover the influence of the variable "critical incident reporting," both being positively correlated $\left(\chi^{2}\right.$ test, $\mathrm{P}=0.03$ ) over units.

\section{DISCUSSION}

This study confirm concerns about medication safety in intensive care units based on observations in single units or small national samples. ${ }^{10-14}$ In five categories of parenteral medication errors at the administration stage we found a total prevalence of 74.5 errors per 100 patient days. In 71\% of errors there was no change in the patient's status, but 12 patients $(0.9 \%$ of the total study population) experienced permanent harm or died. Considering that this number, derived from self reports, might underestimate the frequency and consequences of errors, these results might be of even greater clinical relevance. Our study shows that the administration of parenteral medication is a weak point in patients' safety in intensive care. As results are based 
on data from 113 participating units worldwide, this problem is not attributable to suboptimal care in a few individual units but represents a common pattern. In fact, only $19 \%$ of participating units reported no parenteral medication errors at the administration stage during the 24 hour observation period.

The frequency of errors we found is in line with several other observations in intensive care. Results from different studies are difficult to compare, however, because of differing definitions and methods of detecting errors. Thus, reported error rates in medication administration range from $3.3 \%$ to $6.2 \%, 6.5 \%,{ }^{14-16}$ and up to $56 \%,{ }^{11}$ depending on factors such as the inclusion or exclusion of different routes of administration as well as timing errors. In a study by van den Bemt, an error frequency of $56 \%$ fell to $34 \%$ when they excluded timing errors. ${ }^{11}$ Although $75 \%$ of all medication errors in our study were related to wrong timing or missed medication, and thus seemingly less serious, the potential impact of such occurrences should not be underestimated. In fact, more than half of the errors

Table 6 | Odds ratios* $(\mathrm{OR})$ for occurrence of at least one error in parenteral drug administration in intensive care unit (ICU). Univariate logistic regression

\begin{tabular}{|c|c|c|c|}
\hline Variable & Variable measurement $\dagger$ & OR $(95 \% \mathrm{Cl})$ & $P$ value \\
\hline \multicolumn{4}{|c|}{ All observed types of parenteral drug administration errors } \\
\hline ICU size (beds) & 1 & $1.02(1.01$ to 1.03$)$ & $<0.01$ \\
\hline ICU type: medical & 1 & $0.64(0.42$ to 0.96$)$ & 0.03 \\
\hline ICU type: mixed & 1 & 1.57 (1.04 to 2.38$)$ & 0.03 \\
\hline Patients per nurse & 1 & $1.26(1.04$ to 1.54$)$ & 0.02 \\
\hline CIRS in place & Yes/no & $0.67(0.53$ to 0.84$)$ & $<0.01$ \\
\hline $\begin{array}{l}\text { Infusions previously prepared by } \\
\text { pharmacist }\end{array}$ & Yes/no & $1.32(1.02$ to 1.70$)$ & 0.03 \\
\hline $\begin{array}{l}\text { No of different types of infusion } \\
\text { pumps }\end{array}$ & 1 & 0.89 (0.81 to 0.99$)$ & 0.03 \\
\hline Routine check at shift change & Yes/no & $0.63(0.50$ to 0.81$)$ & $<0.01$ \\
\hline Labelling of syringes & Yes/no & $0.61(0.44$ to 0.86$)$ & $<0.01$ \\
\hline Occupancy rate (\%) & 10 & $1.02(1.00$ to 1.05$)$ & 0.04 \\
\hline Relative turnover & 1 & $0.75(0.60$ to 0.93$)$ & 0.01 \\
\hline \multicolumn{4}{|c|}{ Errors of commission (wrong dose, wrong drug, wrong route) } \\
\hline Hospital size (beds) & 100 & 1.05 (1.02 to 1.08$)$ & $<0.01$ \\
\hline ICU size (beds) & 1 & $1.02(1.01$ to 1.03$)$ & $<0.01$ \\
\hline Patients per nurse & 1 & 1.51 (1.10 to 2.07$)$ & 0.01 \\
\hline Patients per physician & 1 & $1.10(1.01$ to 1.20$)$ & 0.03 \\
\hline ICU beds per nurse & 1 & 1.35 (1.02 to 1.77$)$ & 0.03 \\
\hline CIRS† in place & Yes/no & $0.36(0.24$ to 0.54$)$ & $<0.01$ \\
\hline $\begin{array}{l}\text { Infusions previously prepared by } \\
\text { pharmacist }\end{array}$ & Yes/no & $2.32(1.57$ to 3.41$)$ & $<0.01$ \\
\hline $\begin{array}{l}\text { Electronic prescribing system in } \\
\text { use }\end{array}$ & Yes/no & $0.62(0.40$ to 0.95$)$ & 0.03 \\
\hline \multicolumn{4}{|l|}{ Errors requiring an intervention } \\
\hline CIRS in place & Yes/no & 0.44 (0.26 to 0.75$)$ & $<0.01$ \\
\hline $\begin{array}{l}\text { Electronic prescribing system in } \\
\text { use }\end{array}$ & Yes/no & $0.43(0.23$ to 0.82$)$ & 0.01 \\
\hline No of different types of perfusors & 1 & 1.16 (1.04 to 1.29$)$ & 0.01 \\
\hline Labelling of syringes & Yes/no & 0.31 (0.18 to 0.56$)$ & $<0.01$ \\
\hline
\end{tabular}

CIRS=critical incident reporting system.

*Odds ratios calculated by using dependent variable "occurrence of at least one medication error" with patients as unit of analysis. Table displays unit related variables reaching significance in different sets of error. †Increment or binary. with reported subsequent serious harm were attributable to errors of omission. At first glance this might be surprising, but, besides the obvious effect of missing a dose, even a delay in administration can have potentially serious consequences. For example, Kumar et al observed a negative and time dependent effect on mortality related to a delayed administration of antibiotics in patients in septic shock. ${ }^{17}$

\section{How and why errors occur}

One of the most important steps in improving patients' safety is to understand how and why errors occur. ${ }^{18} \mathrm{We}$ identified several contributing factors for errors in the administration of parenteral medication, though our observational design means we cannot confirm any causal relation. Univariate and multivariate analyses showed that more severely ill patients, who receive a higher level of care with the corresponding increased use of parenteral medication, are more likely to experience a medication error. This finding directly reflects the complexity of care and thus the increased opportunity for error. A coupling of an increase in complexity and the risk for error is consistent with the existing literature. ${ }^{519-21}$

With respect to potential preventive measures, unit related factors are the most important starting point for changes in the management of care. Most medication errors occurred during routine care of patients and not during extraordinary situations. In accordance with several other studies, ${ }^{22-24}$ we found that increased workload - as measured by the patient to nurse ratio, the occupancy rate, and the ratio of beds per nurse - is associated with a higher risk for adverse events. In a subjective assessment of staff, workload, stress, and fatigue were seen as a contributing factor for error in $33 \%$ of all events. This is similar to the results of a recent investigation showing that nurses viewed heavy workload as a contributing factor in 37\% of medication errors. ${ }^{25} \mathrm{~A}$ more complex effect was related to the size of the participating units: the complexity of organisation and communication in a given unit increases with the number of beds and makes the system more prone to error. When we divided the number of admitted and discharged patients by the number of beds in a given unit (relative turnover), however, this ratio showed a decreased risk for adverse events in units with more beds in relation to the turnover of patients. Not surprisingly, staff reported communication, whether oral or written, as a frequent contributing factor to error.

Another organisational aspect concerns the preparation of infusions and syringes. Interestingly, the provision of infusions previously prepared by a pharmacist increased the risk for a medication error. In contrast, the risks for such an event were lower when nurses labelled syringes that they themselves had prepared. This can be seen as an example of reducing complexity and avoiding gaps in information and communication in the process of care by preparing medication at the place it is needed. A further finding is in an expression of the impact of increased complexity 
Table $7 \mid$ Odds ratios ${ }^{\star}(\mathrm{OR})$ for occurrence of at least one parenteral drug administration error in intensive care unit (ICU). Stepwise multiple logistic regression

\begin{tabular}{|c|c|c|c|}
\hline Variable & Variable measurement $\dagger$ & OR $(95 \% \mathrm{Cl})$ & $P$ value \\
\hline \multicolumn{4}{|c|}{ All observed types of parenteral drug administration errors } \\
\hline \multicolumn{4}{|l|}{ Patient related variables: } \\
\hline $\begin{array}{l}\text { No of parenteral } \\
\text { administrations }\end{array}$ & 1 & $1.06(1.04$ to 1.08$)$ & $<0.01$ \\
\hline No of organ failures & 1 & $1.19(1.05$ to 1.34$)$ & $<0.01$ \\
\hline \multicolumn{4}{|l|}{ NEMS item: } \\
\hline Basic monitoring & Yes/no & $0.19(0.07$ to 0.49$)$ & $<0.01$ \\
\hline IV medication & Yes/no & $2.73(1.39$ to 5.36$)$ & $<0.01$ \\
\hline Specific interventions in ICU & Yes/no & $1.50(1.14$ to 1.96$)$ & $<0.01$ \\
\hline \multicolumn{4}{|l|}{ ICU related variables: } \\
\hline ICU size (beds) & 1 & 1.01 (1.00 to 1.02$)$ & 0.04 \\
\hline Patients per nurse & 1 & $1.30(1.03$ to 1.64$)$ & 0.03 \\
\hline CIRS in place & Yes/no & $0.69(0.53$ to 0.90$)$ & $<0.01$ \\
\hline Routine check at shift change & Yes/no & $0.68(0.52$ to 0.90$)$ & $<0.01$ \\
\hline Occupancy rate (\%) & 10 & $1.03(1.00$ to 1.05$)$ & 0.03 \\
\hline Relative turnover & 1 & 0.73 (0.57 to 0.93$)$ & 0.01 \\
\hline
\end{tabular}

Errors of commission (wrong dose, wrong drug, wrong route)

Patient related variables:

\begin{tabular}{llll}
$\begin{array}{c}\text { No of parenteral } \\
\text { administrations }\end{array}$ & 1 & $1.05(1.02$ to 1.07$)$ & $<0.01$ \\
\hline $\begin{array}{c}\text { NEMS item: } \\
\begin{array}{c}\text { Multiple vasoactive } \\
\text { medication }\end{array}\end{array}$ & Yes/no & $2.43(1.41$ to 4.18) & $<0.01$
\end{tabular}

medication

ICU related variables:

\begin{tabular}{lccc}
\hline Patients per physician & 1 & $1.12(1.02$ to 1.23$)$ & 0.01 \\
\hline CIRS in place & Yes/no & $0.34(0.22$ to 0.52$)$ & $<0.01$ \\
\hline $\begin{array}{c}\text { Infusions previously prepared } \\
\text { by pharmacist }\end{array}$ & Yes/no & $2.36(1.55$ to 3.60$)$ & $<0.01$
\end{tabular}

by pharmacist

Errors requiring an intervention

Patient related variables:

\begin{tabular}{llll}
$\begin{array}{c}\text { No of parenteral } \\
\text { administrations }\end{array}$ & 1 & $1.08(1.05$ to 1.12$)$ & $<0.01$ \\
\hline
\end{tabular}

dministrations

NEMS item:

\begin{tabular}{llll}
\hline $\begin{array}{c}\text { Multiple vasoactive } \\
\text { medication }\end{array}$ & Yes/no & $2.63(1.37$ to 5.07$)$ & $<0.01$ \\
\hline $\begin{array}{c}\text { Specific interventions } \\
\text { outside ICU }\end{array}$ & Yes/no & $2.25(1.16$ to 4.39) & 0.02 \\
\hline $\begin{array}{l}\text { ICU related variables: } \\
\begin{array}{l}\text { Electronic prescribing system in } \\
\text { use }\end{array}\end{array}$ & Yes/no & $0.32(0.16$ to 0.64$)$ & $<0.01$ \\
\hline
\end{tabular}

NEMS=nine equivalents of nursing manpower use score; CIRS=critical incident reporting system.

*Odds ratios calculated by using dependent variable "occurrence of at least one medication error" with patients as unit of analysis. Model accounts for patient and ICU characteristics and different sets of error.

†ncrement or binary.
Thus, our results suggest that the implementation of several achievable measures might enhance the safe process of parenteral drug administration in intensive care units. With respect to the daily process of care, the most robust results refer to the beneficial effect of routine checks of perfusors and infusion pumps at every nursing shift change and the existence of a critical incident reporting system. In addition, unit administrators should be aware that an increasing number of beds and an increasing ratio of patients to nurses are risk factors for the occurrence of parenteral administration errors. As trainees were involved in more than half of the errors with reported subsequent serious harm, the supervision of trainees should be a further focus of concern. Given the frequency and impact of errors of omission, preventive measures for this type of error should be investigated in further studies. As both types of parenteral drug administration errors - omission and commission - might be reducible by technical measures such as aided recall, drug identification (such as bar codes), and proper design of infusion pumps, this should also be a further focus of research.

\section{Limitations}

Although we aimed to acquire extended information about the structure and organisation of participating units, components that have been shown to influence the occurrence of errors-such as variations in unit organisation $^{11}$ and different formats and cultures of communication $^{37}$ - are difficult to measure and were outside the scope of our 24 hour observation. With self reporting, it is important to acknowledge several problems in assessing errors. Different formats of data collection, such as chart review or incident reporting, will lead to different findings. ${ }^{29}$ Furthermore, as shown by several investigators, a self reporting method carries the risk of under-reporting. ${ }^{33031}$ The use of external observers might be considered the ideal, but this method takes up a lot of resources and introduces the bias of staff behaving differently while under observation (Hawthorne effect). Because we used facilitated reporting by a structured questionnaire for the occurrence of a focused set of events in a short period of time, we are confident that these problems were minimised.

This focus on the specific problem of parenteral drug administration might explain the higher rate of medication errors than in the previous study (SEE 1), which looked simultaneously at errors in several other domains and did not include medication related errors of omission. ${ }^{5}$ Moreover, the possibility of volunteer bias needs to be considered because the units studied were self selecting in both studies and only a third of units in the current study had participated in SEE 1. Paradoxically, the high frequency of medication errors raises concerns about over-reporting. Although duplicate reporting was considered highly unlikely because of the use of a structured questionnaire and because we excluded suspected duplicates from the analysis, we cannot entirely rule out the possibility of overreporting. Finally, we could not establish a detailed 


\section{WHAT IS ALREADY KNOWN ON THIS TOPIC}

Serious concerns about medication safety in intensive care units have been raised, mostly in single centre studies

The extent to which medication safety represents a common problem in units is unknown

Cause of medication errors is related to human factors and, more important, system failures, but preventive factors are only partly explored

\section{WHAT THIS STUDY ADDS}

The administration of parenteral medication seems to represent a common pattern of weakness in patients' safety in intensive care units

Organisational factors such as error reporting systems and routine checks can reduce the risk of parenteral administration errors at the administration stage

validation of the reported impact of medication errors. One important reason is that we wanted to avoid undue apprehension on the part of the staff of participating units; the flow of information regarding patients' harm was kept formalised, structured, and unidirectional so the staff would not fear further investigation. As a consequence of this approach, we could obtain only limited information about how errors caused the reported harm. On the other hand, even a sophisticated audit might not be able to distinguish, in every case, between the impact of an error and the result of the natural course of disease.

We thank Mary McKenney for editorial advice, Gerhard Krenn for programming the study website, and the staff of all the units that contributed to the study. A list of people in charge of the study at the unit level can be found at www.hsro-esicm.org.

Contributors: AV, MC, BG, RM, and PM contributed to the design of the study. AV and PM managed organisation and data collection. AV, BM, and PB analysed the data. BM and PB designed and carried out the statistica analysis. AV wrote the draft of the report and is guarantor. All authors contributed to the final writing of the report and approved the final version. Funding: The SEE study was supported and funded by the Austrian Center for Documentation and Quality Assurance in Intensive Care Medicine (ASDI) and endorsed by the European Society of Intensive Care Medicine (ESICM).

Competing interests: None declared.

Ethical approval: Because the study was observational and no additiona interventions were performed, the need for informed consent was waived by the institutional review board. Each unit, however, was made responsible for obtaining local permissions, as necessary, according to local regulations.

1 Sheldon T. Dutch study shows that $40 \%$ of adverse incidents in hospital are avoidable. BMJ 2007;334:925

2 Sexton JB, Thomas EJ, Helmreich RL. Error, stress, and teamwork in medicine and aviation: cross sectional surveys. $B M J$ 2000;320:745-9.

3 Donchin Y, Gopher D, Olin M, Badihi Y, Biesky M, Sprung CL, et al. A look into the nature and causes of human errors in the intensive care unit. Crit Care Med 1995;23:294-300.

4 Rothschild JM, Landrigan CP, Cronin JW, Kaushal R, Lockley SW, Burdick $E$, et al. The critical care safety study: the incidence and nature of adverse events and serious medical errors in intensive care. Crit Care Med 2005;33:1694-700.

5 Valentin A, Capuzzo M, Guidet B, Moreno RP, Dolanski L, Bauer P, et al. Patient safety in intensive care: results from the multinational sentinel events evaluation (SEE) study. Intensive Care Med 2006;32:1591-8.
6 ASHP guidelines on preventing medication errors in hospitals. Am J Hosp Pharm 1993;50:305-14.

7 Wasserfallen JB, Butschi AJ, Muff P, Biollaz J, Schaller MD, Pannatier A, et al. Format of medical order sheet improves security of antibiotics prescription: the experience of an intensive care unit. Crit Care Med 2004;32:655-9.

8 Vincent JL, Moreno R, Takala J, Willatts S, De Mendonca A, Bruining H, et al. The SOFA (sepsis-related organ failure assessment) score to describe organ dysfunction/failure. On behalf of the Working Group on Sepsis-Related Problems of the European Society of Intensive Care Medicine. Intensive Care Med 1996;22:707-10.

9 Reis Miranda D, Moreno R, lapichino G. Nine equivalents of nursing manpower use score (NEMS). Intensive Care Med 1997;23:760-5.

10 Tissot E, Cornette C, Demoly P, Jacquet M, Barale F, Capellier G. Medication errors at the administration stage in an intensive care unit. Intensive Care Med 1999;25:353-9.

11 Van den Bemt PM, Fijn R, van der Voort PH, Gossen AA, Egberts TC, Brouwers JR. Frequency and determinants of drug administration errors in the intensive care unit. Crit Care Med 2002;30:846-50.

12 Herout PM, Erstad BL. Medication errors involving continuously infused medications in a surgical intensive care unit. Crit Care Med 2004;32:428-32.

13 Parshuram CS, Ng GY, Ho TK, Klein J, Moore AM, Bohn D, et al. Discrepancies between ordered and delivered concentrations of opiate infusions in critical care. Crit Care Med 2003;31:2483-7.

14 Calabrese AD, Erstad BL, Brandl K, Barletta JF, Kane SL, Sherman DS Medication administration errors in adult patients in the ICU. Intensive Care Med 2001;27:1592-8.

15 Fahimi F, Ariapanah P, Faizi M, Shafaghi B, Namdar R, Ardakani MT. Errors in preparation and administration of intravenous medications in the intensive care unit of a teaching hospital: an observational study. Aust Crit Care 2008;21:110-6.

16 Kopp BJ, Erstad BL, Allen ME, Theodorou AA, Priestley G. Medication errors and adverse drug events in an intensive care unit: direct observation approach for detection. Crit Care Med 2006;34:415-25.

17 Kumar A, Roberts D, Wood KE, Light B, Parrillo JE, Sharma S, et al. Duration of hypotension before initiation of effective antimicrobial therapy is the critical determinant of survival in human septic shock. Crit Care Med 2006;34:1589-96.

18 Valentin A, Bion J. How safe is my intensive care unit? An overview of error causation and prevention. Curr Opin Crit Care 2007;13:697-702.

19 Bracco D, Favre JB, Bissonnette B, Wasserfallen JB, Revelly JP, Ravussin $\mathrm{P}$, et al. Human errors in a multidisciplinary intensive care unit: a 1-year prospective study. Intensive Care Med 2001;27:137-45.

20 Cullen DJ, Sweitzer BJ, Bates DW, Burdick E, Edmondson A, Leape LL. Preventable adverse drug events in hospitalized patients: a comparative study of intensive care and general care units. Crit Care Med 1997;25:1289-97.

21 Webster CS. The nuclear power industry as an alternative analogy for safety in anaesthesia and a novel approach for the conceptualisation of safety goals. Anaesthesia 2005;60:1115-22.

22 Tarnow-Mordi WO, Hau C, Warden A, Shearer AJ. Hospital mortality in relation to staff workload: a 4-year study in an adult intensive-care unit. Lancet 2000;356:185-9.

23 Ream RS, Mackey K, Leet T, Green MC, Andreone TL, Loftis LL, et al. Association of nursing workload and unplanned extubations in a pediatric intensive care unit. Pediatr Crit Care Med 2007;8:366-71.

24 Hugonnet S, Chevrolet JC, Pittet D. The effect of workload on infection risk in critically ill patients. Crit Care Med 2007;35:76-81.

25 Tang Fl, Sheu SJ, Yu S, Wei IL, Chen CH. Nurses relate the contributing factors involved in medication errors. J Clin Nurs 2007;16:447-57.

26 McCauley K, Irwin RS. Changing the work environment in ICUs to achieve patient-focused care: the time has come. Chest 2006;130:1571-8.

27 Zohar D, Livne Y, Tenne-Gazit O, Admi H, Donchin Y. Healthcare climate: a framework for measuring and improving patient safety. Crit Care Med 2007:35:1312-7.

28 Minvielle E, Aegerter P, Dervaux B, Boumendil A, Retbi A, Jars-Guincestre MC, et al. Assessing organizational performance in intensive care units: a French experience./ Crit Care 2008;23:236-44.

29 Beckmann U, Bohringer C, Carless R, Gillies DM, Runciman WB, Wu AW, et al. Evaluation of two methods for quality improvement in intensive care: facilitated incident monitoring and retrospective medical chart review. Crit Care Med 2003;31:1006-11.

30 Vincent C, Stanhope N, Crowley-Murphy M. Reasons for not reporting adverse incidents: an empirical study. J Eval Clin Pract 1999;5:13-21.

31 Stanhope N, Crowley-Murphy M, Vincent C, O’Connor AM, Taylor-Adams SE. An evaluation of adverse incident reporting. J Eval Clin Pract 1999;5:5-12.

Accepted: 5 December 2008 